\title{
LETTERS
}

\section{Moving surgical care out of hospitals to reduce wait times}

I read the interviews regarding wait times in the Canadian health care system ${ }^{1}$ with great interest, but also with a sense of disappointment. For all the proposals made by the interviewees to improve wait times, the glaringly obvious one of taking surgical care outside of the hospital was not even mentioned. Ambulatory surgical centres (ASCs), common in many other countries, have very little presence in Canada. ASCs can easily perform simple day surgeries for healthy patients at a lower cost than hospitals and with shorter wait times, with no sacrifice in quality of care. ${ }^{2,3}$

Transferring smaller, insured, elective surgical work into publicly funded ASCs would move a substantial amount of patient care out of hospitals and simultaneously open hospital spaces for other care needs. In turn, this would help to directly decrease wait times and end "hallway medicine."

In 2012, the nonpartisan Drummond Report was published in Ontario, ${ }^{4}$ which proposed that health care shift emphasis away from hospitals to other methods of care delivery. This was suggested not only for improved quality of care, but for better timeliness, efficiency and other operational quality measures. Using an ASC model for certain publicly funded surgeries is a logical solution, consistent with the Drummond Report's suggestions, and would be a meaningful step to improving elective surgical care for Canadian citizens.

It is high time that policy-makers consider an ASC approach as a means to improve the quality of surgical care for Canadians.

\section{Brian Rotenberg MD MPH}

Professor and residency program director, Otolaryngology - Head and Neck Surgery, Schulich School of Medicine and Dentistry, Western University, London, Ont.

- Cite as: CMAJ 2021 January 25;193: E138. doi: 10.1503/cmaj.77461

\section{References}

1. Vogel L. How can Canada improve worsening wait times? CMAJ 2020;192:E1079-80.

2. Barua B, Palacios M, Emes J. The sustainability of health care spending in Ontario 2017 [report]. Vancouver: Fraser Institute; 2017. Available: www.fraserinstitute.org/sites/default/files/ sustainability-of-health-care-spending-in-canada -2017.pdf (accessed 2018 Sept. 15).

3. Ahmad J, Ho OA, Carman WW, et al. Assessing patient safety in Canadian ambulatory surgery facilities: a national survey. Plast Surg (Oakv) 2014; 22:34-8.

2. Drummond D, Giroux D, Pigott S. Commission on the reform of Ontario's public services [report]. Queen's Printer for Ontario; 2012. Available: www. fin.gov.on.ca/en/reformcommission/chapters/ report.pdf (accessed 2020 Nov. 20).

Competing interests: None declared.

Content licence: This is an Open Access article distributed in accordance with the terms of the Creative Commons Attribution (CC BY-NC-ND 4.0) licence, which permits use, distribution and reproduction in any medium, provided that the original publication is properly cited, the use is noncommercial (i.e., research or educational use), and no modifications or adaptations are made. See: https://creativecommons.org/ licenses/by-nc-nd/4.0/ 